\title{
Still-water sinking velocity of fecal material from the pelagic tunicate Dolioletta gegenbauri
}

\author{
Don Deibel \\ Ocean Sciences Centre, Marine Sciences Research Laboratory, Memorial University of Newfoundland, St. John's, \\ Newfoundland, Canada A1C 5S7
}

\begin{abstract}
Results of recent models suggest that fecal pellet production by pelagic tunicates should have a major impact on the relative magnitude of export of particulate organic matter from the upper mixed layer of the ocean. However, little is known of the sinking velocities of feces from small salps and doliolids living in continental shelf waters. This study was designed to determine the sinking velocity of fecal pellets from Dolioletta gegenbauri under natural and amended food conditions, and to examine whether sinking behavior is best described by the Stokes or inertial formulations of the force balance equation. Still-water sinking velocity of pellets was determined in the laboratory at $20^{\circ} \mathrm{C}$ and $36.0 \% \mathrm{~S}$ in a glass cylinder, and ranged from 59 to $405 \mathrm{~m} \mathrm{~d}^{-1}$ Most of the feces produced by specimens fed only naturally occurring particles did not sink. About $70 \%$ of the total variance of the logarithm of sinking velocity of the pellets produced by specimens fed the amended diet was explained by a linear regression against the logarithm of pellet volume. These pellets sank more slowly than was expected based on sinking velocities of the pellets of copepods, euphausiids and salps. Also, the rate of increase of sinking velocity with increasing pellet size (which was a linear function of diameter) was lower than predicted by the Stokes equation (i.e. where sinking velocity of spherical particles $\propto$ diam. ${ }^{2}$ ), indicating that the pellets fell in an intermediate zone between the Stokes and inertial forms of the force balance equation
\end{abstract}

\section{INTRODUCTION}

Results of recent models indicate that the relative magnitude of export of organic matter from the upper mixed layer of the ocean should depend on the abundance, physiology and population dynamics of pelagic tunicates (Andersen \& Nival 1988, Michaels \& Silver 1988). Large fecal pellets produced by oceanic salps sink at high velocities, from 100 's of $\mathrm{m}$ to several $\mathrm{km}$ $\mathrm{d}^{-1}$, and often dominate the mass flux of organic matter (Matsueda et al. 1986, Bathmann 1988, Morris et al. 1988). There is uncertainty however, about whether fecal pellets produced by small neritic salps and doliolids contribute primarily to recycling or to export (Pomeroy \& Deibel 1980, Bruland \& Silver 1981, Madin 1982, Pomeroy et al. 1984).

Dolioletta gegenbauri is common in the South Atlantic Bight of the USA (SAB: Cape Canaveral, Florida, to Cape Hatteras, N. Carolina) often forming population irruptions covering 100's of $\mathrm{km}^{2}$ in association with phytoplankton blooms resulting from nutrients up- welled by Gulf Stream frontal eddies (Deibel 1985, Paffenhöfer \& Lee 1987). Pomeroy \& Deibel (1980) found that many of the fecal pellets of $D$. gegenbauri sank slowly if at all, and suggested that they may have a residence time in the water column of the SAB of $>5 \mathrm{~d}$, more than enough time for all of the labile organic carbon to be removed from them by microorganisms (Pomeroy et al. 1984). However, Bruland \& Silver (1981) found the fecal pellets of $D$. gegenbauri to sink at substantial velocities (41 to $208 \mathrm{~m} \mathrm{~d}^{-1}$ ). If the fecal pellets of doliolids in the $S A B$ sink at similar velocities, their residence time in the water column would be $<2 d$, and much organic carbon would be available for export to the benthos. Are these views really disparate, or can they be accounted for by biological and hydrodynamic factors that regulate the sinking behavior of small fecal particles in the ocean?

This study was designed to determine the sinking velocity of fecal pellets produced by Dolioletta gegenbauri under natural and amended food conditions, and to examine whether their sinking behavior is best 
described by the Stokes form of the force balance equation (i.e. the low Reynolds number case with drag dependent primarily on viscous forces and sinking velocity $\propto$ diam. ${ }^{2}$ ) or by the high Reynolds number (Re) formulation, with drag dependent primarily on inertial forces and sinking velocity $\propto$ diam. ${ }^{0.5}$ (Komar \& Taghon 1985).

\section{MATERIALS AND METHODS}

Still-water sinking velocity was measured for pellets $<24 \mathrm{~h}$ old, produced by a mixture of gonozooids and phorozooids of Dolioletta gegenbauri ranging in length from 2.7 to $7.0 \mathrm{~mm}$. Some of the specimens were captured in the field while others were released by adults held in the laboratory. They were fed either naturally occurring particulate matter from the collection site (pre-filtered through $180 \mu \mathrm{m}$ mesh), or natural particles amended with a mixture of Isochrysis galbana, Peridinium trochoideum and Thalassiosira fluviatilis from laboratory cultures. These species were selected to represent the types of food encountered by $D$. gegenbauri in outer continental shelf waters of the SAB (Deibel 1985). Quantities of algae were added to approximate concentrations found in phytoplankton blooms associated with Gulf Stream frontal eddies where doliolid irruptions are common (Deibel 1985). Collections were made on $18 \mathrm{March} 1980$ southeast of Savannah, Georgia, USA, in water of $18.0^{\circ} \mathrm{C}$ and $36 \% \mathrm{~S}$.

In preparation for sinking velocity determination, fecal pellets were rinsed in filtered seawater to remove adherent particles (Whatman GF/C), and their lengths and diameters determined with a stereomicroscope to the nearest $12 \mu \mathrm{m}$. Still-water sinking velocities were determined in a glass, $100 \mathrm{ml}$ graduated cylinder with an inside diameter of $2.58 \mathrm{~cm}$ and a height of $24.0 \mathrm{~cm}$. Although theoretical calculations suggest that the smaller pellets in this study may be affected by the presence of walls as much as 120 particle diameters away (Vogel 1981), they did not migrate toward the walls nor did their sinking rates depart from the linear relationship shown in Fig. 1, both indications that the wall effect was minimal. The cylinder was filled with filtered seawater with a salinity of $36 \%$ the day before sinking velocities were determined. The experiments were done in a controlled temperature room $\left(20^{\circ} \mathrm{C}\right)$. Pellets were released gently into the cylinder just beneath the surface of the water with a fine pipet. After allowing each pellet to sink $7 \mathrm{~cm}$ to eliminate momentum from its release (Bienfang, 1980) the time required for it to sink over 3 contiguous intervals of $3.8 \mathrm{~cm}$ was measured, and a mean sinking velocity calculated. Pellets which did not sink within 3 min of release were considered to be neutrally buoyant.

\section{RESULTS}

There was no difference between the sinking velocities of pellets from individuals collected in the field vs those from individuals born in the laboratory (determined by visual inspection of a scatter plot of all data), so data were pooled from all individuals before analysis. The smallest prolate spheroid pellet was $96 \times$ $160 \mu \mathrm{m}$ and the largest $480 \times 2688 \mu \mathrm{m}$. The smallest spherical pellet was $220 \mu \mathrm{m}$ in diameter and the largest $840 \mu \mathrm{m}$. Thus, pellets of various shapes were available for a wide range of volumes, from $1 \times 10^{6}$ to $3 \times 10^{8}$ $4 \mathrm{~m}^{3}$.

The sinking velocity of pellets produced by doliolids fed the amended diet ranged from 59 to $405 \mathrm{~m} \mathrm{~d}^{-1}$ ( $\overline{\mathrm{x}} \pm$ $\mathrm{SD}=129 \pm 13, \mathrm{n}=28$; Fig. 1). Two small pellets of 1.2 $\times 10^{6}$ and $2.0 \times 10^{7} \mu \mathrm{m}^{3}$ did not sink and are not shown in Fig. 1. Of the total variance of the logarithm of sinking velocity, $70 \%$ was explained by a linear regression vs the logarithm of pellet volume (Fig. 1) The exponent of 0.32 implies that sinking velocity was a function of some linear dimension of the pellets (e.g diameter), as volume is dependent on the cube of diameter, and thus sinking velocity $(\mathrm{U}) \propto \mathrm{V}^{0.32}$, or to (diam. $\left.{ }^{3}\right)^{0.32}$, which is equivalent to $\mathrm{U} \propto$ diam. ${ }^{0.96}$. Variability of sinking velocity during the descent of pellets was low, with the range of triplicate measurements

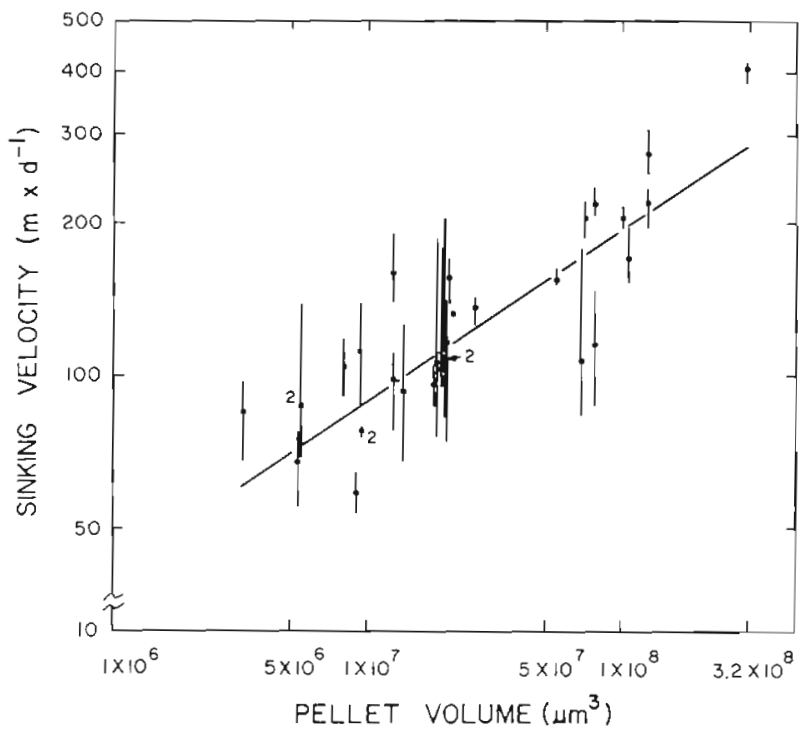

Fig. 1 Logarithm of mean sinking velocity $\left(m \mathrm{~d}^{-1}\right)$ vs logarithm of pellet volume $\left(u^{3}\right)$ for feces of Dolioletta gegenbauri fed a mixture of naturally occurring particulate matter and laboratory-grown phytoplankton (amended diet). For experimental conditions see 'Materials and methods' The line represents the least-squares linear regression equation $\log _{10}$ sinking rate $=0.32 \log _{10}$ (volume $)-0.28\left(n=28, r^{2}=0.70\right.$. standard error of the estimate $\equiv 0.10$. Vertical lines represent the range of triplicate measurements of sinking velocity for a single pellet except where shown ( 3 points are duplicates) 
generally $<10 \%$ of the mean. Most of the fecal pellets produced by individuals fed only naturally occurring particles did not sink (data not shown), perhaps due to the nature of the diet or to differences in individual feeding behavior (see 'Discussion').

\section{DISCUSSION}

\section{Sinking velocity and diet}

Pomeroy et al. (1984) found newly-captured salps and doliolids to have a wide range of gut fullness within a single sample, with many specimens having empty guts. Large variance between individuals in feeding rate and behavior may be typical of marine zooplankton generally (Bruland \& Silver 1981, Bamstedt 1988). Individuals with partially-filled guts produced flocculent fecal ribbons just after capture that did not sink and that disintegrated easily (Pomeroy et al. 1984). I believe these qualities are not artifacts of containment because we have found repeatedly that small pelagic tunicates held in a rich food supply produce compact feces that sink at measurable rates (Pomeroy \& Deibel 1980, Pomeroy et al. 1984; Fig. 1 in this paper). Thus, doliolids fed naturally occurring particles in this study most likely produced fecal pellets that did not sink (see 'Results') because of either a low concentration of food or a scarcity of armored cells such as diatoms and dinoflagellates in the diet (Bruland \& Silver 1981).

Although uninvestigated for tunicates, it is well known that food concentration and diet may affect the sinking rate of fecal pellets produced by crustacean zooplankton by altering their density, compactness or size (see references in Bienfang 1980). Unfortunately, the sign of these effects is not always predictable. Fowler \& Small (1972) found laboratory-determined sinking velocities of zooplankton fecal pellets to be underestimates of in situ velocities due to the low primary density of particles offered as food in the laboratory. Bienfang (1980) found that zooplankton fed diatoms produced dense feces that sank at higher velocities than those of lesser density produced when the animals were fed phytoflagellates. Turner (1977) found no effect of composition of the diet on the sinking velocities of pellets produced by pontellid copepods. Alldredge \& Gotschalk (1988) believed laboratory estimates of the sinking velocity of marine snow were overestimates of in situ velocities due to the collapse and condensation of flocculent aggregates held in containers.

It is difficult to extrapolate observations from copepods to pelagic tunicates, because tunicates do not have hard mouthparts with which to crush and compact their prey, suggesting that differences in the size or density of food items may be transferred directly to their fecal pellets. I have duplicated the full range of observed sinking velocities of fecal material of Dolioletta gegenbauri (from 0 to several $100 \mathrm{~m} \mathrm{~d}^{-1}$ ) by manipulating the diet, from that typical of non-phytoplankton bloom conditions (the 'natural' diet) to that typical of outer shelf blooms (the amended diet). Thus, no single relationship between size and sinking velocity of doliolid fecal material can be assumed for estimating maximum vertical flux under all conditions, without additional information on the nature of the diet and on the excess density of the pellets.

\section{Excess density}

The fecal pellets of Dolioletta gegenbauri sank at about $1 / 2$ the velocity that was expected based on their size, in comparison to the pellets of copepods, euphausiids and salps (Fig. 2). Bruland \& Silver (1981) also found larger pellets of $D$. gegenbauri to sink slowly, at about $1 / 10$ of the expected velocity based on the same trend line (Fig. 2). Why should this be so? Doliolid fecal pellets do not appear to have a peritrophic membrane as do the pellets of copepods and

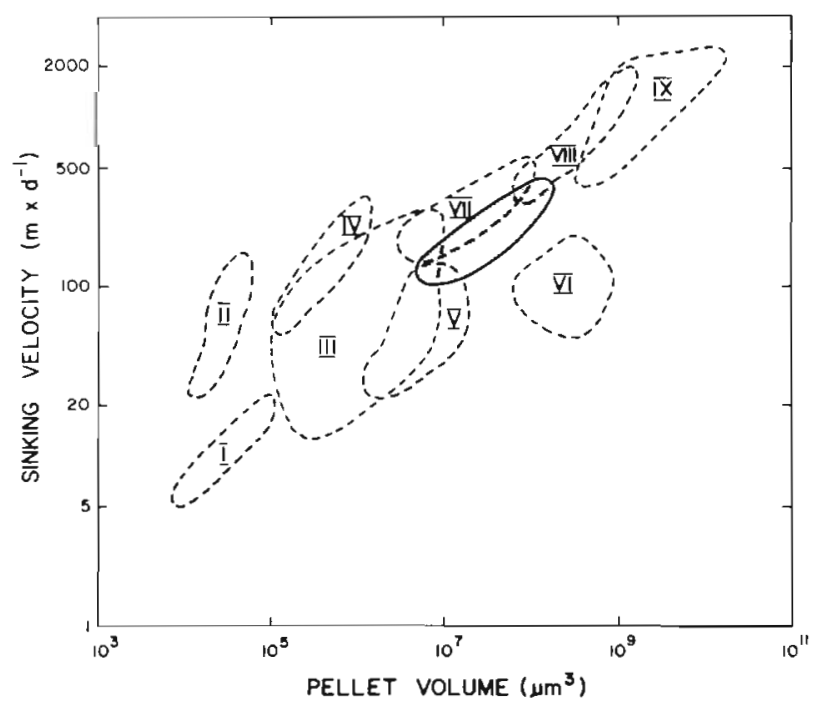

Fig. 2. Range of the logarithm of sinking velocity ( $\mathrm{m} \mathrm{d}^{-1}$ ) vs the logarithm of pellet volume $\left(\mu \mathrm{m}^{3}\right)$ for a variety of macrozooplankton, adapted from a figure by Bruland \& Silver (1981). Data shown are: I, copepod nauplii and copepodids (Paffenhöfer \& Knowles 1979); II, Oikopleura dioica (Gorsky et al. 1984); III, small and large copepods (Small et al. 1979); IV, naturally occurring fecal material (Smayda 1969); V, Pontella meadii (Turner 1977); VI, Dolioletta gegenbauri (Bruland \& Silver 1981); VII, euphausiids (Small et al. 1979); VIII, Corolla spectabilis (Bruland \& Silver 1981); IX, salps (Bruland \& Silver 1981, Madin 1982). Shaded area represents data for $D$. gegenbauri from this paper 
salps, making them visually indistinguishable from small, marine snow aggregates (Pomeroy \& Deibel 1980, Bruland \& Silver 1981). Bruland \& Silver (1981) suggested that the lower than expected sinking velocities of salp fecal pellets were due to their low density $\left(1.10 \mathrm{~g} \times \mathrm{cm}^{-3}\right)$ in comparison to the pellets of copepods $\left(1.22 \mathrm{~g} \times \mathrm{cm}^{-3}\right)$, and that the fecal pellets of doliolids were apparently less dense than were salp pellets. These observations indicate that the density of doliolid pellets may be $<1.10 \mathrm{~g} \mathrm{~cm}^{-3}$, less than that of diatoms (1.15 to $1.19 \mathrm{~g} \mathrm{~cm}^{-3}$ i Smayda 1970) and copepod fecal pellets $\left(1.11\right.$ to $1.17 \mathrm{~g} \mathrm{~cm}^{-3}$; Bienfang 1980), and approaching that of marine snow ( $\mathrm{ca} 1.03 \mathrm{~g}$ $\mathrm{cm}^{-3}$; Alldredge \& Gotschalk 1988). By extension of the argument presented by Bruland \& Silver (1981), I suggest that the low excess density of doliolid fecal pellets accounts for their low sinking velocity in comparison to the more compact feces of copepods, euphausiids and salps (Fig. 2)

\section{Linear dependence of sinking velocity on size}

The Reynolds number of the doliolid fecal pellets (using equivalent spherical diameter as the characteristic length) ranged from 0.17 to 3.8 , with a mean $( \pm 95 \% \mathrm{CI})$ of $0.75 \pm 0.29(\mathrm{n}=28)$. Seven pellets had an $\operatorname{Re}>1$. This mean value of $\mathrm{Re}$ is above the conventional limit for application of the Stokes equation (i.e. Re <0.5; Alldredge \& Gotschalk 1988), and falls in a transition zone in plots of the drag coefficient $\left(C_{D}\right)$ vs $R e$ where the formulation of the drag force is complex and crucial to the description of sinking behavior (Vogel 1981). In this range the drag force is not dominated by skin friction alone (as for $\mathrm{Re} \ll 1$ under the Stokesian assumptions), but is a combination of skin friction and the fore-aft pressure differential (i.e. inertial forces). Komar \& Taghon (1985, their Fig. 5) depict a smooth transition from the Stokes range to the inertial range, and thus imply the existence of a continuous shift in the dependence of sinking velocity from the square of particle size (i.e. diam. ${ }^{2}$ ) to the square root of particle size (i.e. diam. ${ }^{0.5}$ ). Thus particles with intermediate $\operatorname{Re}$ (i.e. 0.5 to 5 ) are difficult to describe theoretically, and may have an approximately linear dependence of sinking velocity on size.

Although rarely noted, a linear dependence of sinking velocity on particle size seems to hold for particles from single-celled phytoplankton (Smayda 1970, his Fig. 1, Jackson 1989) to macroscopic fecal pellets of oceanic salps $10^{7}$ times larger by volume (Bruland \& Silver 1981, their Fig. 1). As pointed out by Jackson (1989), the sinking velocities of phytoplankton summarized by Smayda (1970) are related to particle diameter by $U x$ diam. ${ }^{1.17}$. I digitized the data points from the summary figure of Bruland \& Silver (1981, on which Fig. 2 is based) to estimate the relationship between sinking velocity and particle volume for the fecal pellets of a wide range of marine zooplankton. For 5 groups of zooplankton, the slope of the relationship ranged from 0.23 to 0.69 , with an overall slope of 0.38 (Table 1). This corresponds to a dependence of sinking velocity on diameter ranging from 0.69 to 2.07 , with a relationship for all of the data of $U \propto$ diam. ${ }^{1.14}$, almost identical to the relationship for phytoplankton of 1.17 (Jackson 1989) and similar to the relationship I observed for the fecal pellets of Dolioletta gegenbauri of 0.96. Jackson (1989) concludes that the reason for this departure from the Stokes relationship is that the excess density of the particle over the fluid medium $(\Delta \rho)$ for phytoplankton decreases as size increases in accordance with the relation $\Delta \rho \propto \mathrm{d}^{-0.83}$.

It is well known that the excess density of organic particles decreases with increasing size, but we have no idea of the rate of change for doliolid fecal pellets. McCave (1975) reported relationships between $\Delta \rho$ and particle size (i.e. equivalent spherical diameter) for a range of organic particles. After digitizing the data presented in his Fig. 4, I found slopes ranging from -1.19 for organic aggregates examined by Riley (1970) to -0.20 for the fecal pellets of euphausiids studied by Fowler \& Small (1972). Can these values for the change in excess density with particle size be used to understand the relationship between size and sinking velocity for doliolid pellets?

The terminal velocity of a particle falling through a fluid is reached when the buoyancy force plus the drag force are just equal to its weight, i.e. when,

Table 1. Summary of regression analysis of variance of data digitized from Fig. 2 of Bruland \& Silver (1981) relating sinking velocity to volume for the fecal pellets of a variety of marine zooplankton. The general model is $U\left(\mathrm{~m} \mathrm{~d}^{-1}\right)=a \mathrm{Vol}^{\mathrm{b}}$, with units of $\mu \mathrm{m}^{3}$ for volume. For references to original data see legend to Fig. 2 or Bruland \& Silver (1981). n: number of points digitized. The a- $\mathrm{r}^{2}$ is not given for Dolioletta gegenbauri and juvenile copepods because the original data points were not shown in Fig. 2 of Bruland \& Silver (1981) and thus the ' $n$ ' is so small as to make the value of the coefficient of determination meaningless

\begin{tabular}{|lcccr|}
\hline $\begin{array}{l}\text { Source of } \\
\text { fecal pellets }\end{array}$ & Slope & Adjusted-r ${ }^{2}$ & $\begin{array}{c}\text { SE of } \\
\text { estimate }\end{array}$ & $n$ \\
\hline Dolioletta gegenbauri & 0.69 & - & 0.06 & 3 \\
Juvenile copepods & 0.66 & - & 0.01 & 4 \\
Euphausiids & 0.45 & 0.62 & 0.14 & 50 \\
Salps and pteropods & 0.26 & 0.46 & 0.15 & 73 \\
Copepods & 0.23 & 0.23 & 0.23 & 1.12 \\
All of above & 0.38 & 0.84 & 0.24 & 242 \\
$\begin{array}{l}\text { D. gegenbauri } \\
\text { from this study }\end{array}$ & 0.32 & 0.70 & 0.10 & 28 \\
\hline
\end{tabular}




$$
V g^{\prime} \rho_{\mathrm{f}}+1 / 2 \mathrm{C}_{\mathrm{D}} \mathrm{S} \rho_{\mathrm{f}} \mathrm{U}^{2}=\mathrm{V} g^{\prime} \rho_{\mathrm{s}}
$$

where $\mathrm{V}=$ volume of the particle $\left(\mathrm{cm}^{3}\right) ; g^{\prime}=$ gravitation constant ( $\left.981 \mathrm{~cm} \mathrm{~s}^{-1}\right) ; \rho_{f}=$ density of the fluid medium $\left(1.026 \mathrm{~g} \mathrm{~cm}^{-3}\right) ; \mathrm{C}_{\mathrm{D}}=$ dimensionless drag coefficient; $\mathrm{S}=$ maximum cross-sectional area of the particle perpendicular to the direction of sinking $\left(\mathrm{cm}^{2}\right) ; U=$ terminal velocity of the sinking particle $\left(\mathrm{cm} \mathrm{s}^{-1}\right)$; and $\rho_{\mathrm{s}}$ the density of the particle $\left(\mathrm{g} \mathrm{cm}^{-3}\right.$; Alldredge \& Gotschalk 1988). Rearranging for $U$ we have,

$$
\mathrm{U}=\left(2 g^{\prime} \Delta \rho \mathrm{V} / \mathrm{C}_{\mathrm{D}} \rho_{\mathrm{f}} \mathrm{S}\right)^{1 / 2}
$$

where $\Delta \rho=\left(\rho_{\mathrm{s}}-\rho_{\mathrm{f}}\right)$, the excess density of the particle. From this equation one can see that the sinking velocity of a particle depends on its excess density $(\Delta \rho)$, on the inverse of the drag coefficient $\left(C_{D}\right)$, and on the square root of the ratio of its volume to cross-sectional area (V) S). That is,

$$
\mathrm{U} \propto\left(\Delta \rho / \mathrm{C}_{\mathrm{D}} \times \mathrm{V} / \mathrm{S}\right)^{1 / 2}
$$

Excess density is difficult to determine empirically for small particles the size of doliolid fecal particles, and the drag coefficient is best determined from Eq. (2) given information about pellet size, sinking velocity and $\Delta \rho$ (Komar \& Taghon 1985). From data on marine snow aggregates (organic particles which doliolid fecal pellets resemble) presented by Alldredge \& Gotschalk (1988), I have calculated that $C_{D} \propto V / S^{-1.1}$. Substituting this relationship into Eq. (2a) and given that $\Delta \rho \propto \mathrm{V} /$ $\mathrm{S}^{-1.19}$ for organic aggregates (see above, Riley 1970 in McCave 1975), yields $U \propto V / S^{0.95}$, which is within a few $\%$ of the observed slope of 0.96 (Fig. 1). There is need to test these hypothetical relationships between $\Delta \rho, C_{D}$ and size for fecal pellets of pelagic tunicates.

Generally, it is thought that to estimate the potential vertical flux of particles in the sea without using sediment traps one must know the size-specific sinking velocity and excess density of the particle population. However, the excess density of fecal pellets may depend on a complex suite of characteristics, including their porosity, the primary density of individual particles, and the physiological state of living particles within them (Alldredge \& Gotschalk 1988). Although excess density may change predictably with pellet size under conditions of constant food supply, it may vary widely depending on the nature of the particles making up the ingested ration (Bienfang 1980), and must be determined empirically for all sets of conditions pertinent to the field.

Acknowledgements. I thank L. R. Pomeroy for ship support, and R. Thompson, C. C. Morris, and 5 anonymous reviewers for helpful comments on an earlier draft. This work was made possible by the assistance of Capt. J. Rouse and the crew of the RV 'Blue Fin', and is Marine Sciences Research Laboratory contribution no. 712 .

\section{LITERATURE CITED}

Alldredge, A. L., Gotschalk, C. (1988). In situ settling behavior of marine snow. Limnol. Oceanogr. 33: 339-351

Andersen, V., Nival, P. (1988). A pelagic ecosystem model simulating production and sedimentation of biogenic particles: role of salps and copepods. Mar. Ecol. Prog. Ser. 44: $37-50$

Bamstedt, U. (1988). Ecological significance of individual variability in copepod bioenergetics. Hydrobiologia 167/168: $43-59$

Bathmann, U. V. (1988). Mass occurrence of Salpa fusiformis in the spring of 1984 off Ireland: implications for sedimentation processes. Mar. Biol. 97: 127-135

Bienfang, P. K. (1980). Herbivore diet affects fecal pellet settling. Can. J. Fish. Aquat. Sci. 37: 1352-1357

Bruland, K. W., Silver, M. W. (1981). Sinking rates of fecal pellets from gelatinous zooplankton (Salps, Pteropods, Doliolids). Mar. Biol. 63: 295-300

Deibel, D. (1985). Blooms of the pelagic tunicate Dolioletta gegenbauri: are they associated with Gulf Stream frontal eddies? J. mar. Res. 43: 211-236

Fowler, S. W., Small, L. F. (1972). Sinking rates of euphausiid fecal pellets. Limnol. Oceanogr. 17: 293-296

Gorsky, G., Fisher, N. S., Fowler, S. W. (1984). Biogenic debris from the pelagic tunicate Oikopleura dioica and its role in the vertical transport of a transuranium element. Estuar coast. Shelf Sci. 18: 13-23

Jackson, G. A. (1989). Simulation of bacterial attraction and adhesion to falling particles in an aquatic environment. Limnol. Oceanogr 34: 514-530

Komar, P. D., Taghon, G. L. (1985). Analyses of the settling velocities of fecal pellets from the subtidal polychaete Amphicteis scaphobranchiata. J. mar. Res. 43: 605-614

Madin, L. P. (1982). Production, composition and sedimentation of salp fecal pellets in oceanic waters. Mar. Biol. 67: $39-45$

Matsueda, H., Handa, N., Inoue, I., Takano, H. (1986). Ecological significance of salp fecal pellets collected by sediment traps in the eastern North Pacific. Mar. Biol. 91: 421-431

McCave, I. N. (1975). Vertical flux of particles in the ocean. Deep Sea Res. 22: 491-502

Michaels, A. F., Silver, M. W. (1988). Primary production, sinking fluxes and the microbial food web. Deep Sea Res. 35: $473-490$

Morris, R. J., Bone, Q., Head, R., Braconnot, L.-C., Nival, P. (1988). Role of salps in the flux of organic matter to the bottom of the Ligurian Sea. Mar. Biol. 97: 237-241

Paffenhofer, G.-A., Knowles, S. C. (1979). Ecological implications of fecal pellet size, production and consumption by copepods. J. mar. Res. 37: 35-49

Paffenhöfer, G.-A., Lee, T. N. (1987). Development and persistence of patches of thaliacea. S. Afr. J. mar. Sci. 5: 305-318

Pomeroy, L. R., Deibel, D. (1980). Aggregation of organic matter by pelagic tunicates. Limnol. Oceanogr. 25: 643-652

Pomeroy, L. R., Hanson, R. B., McGillivary, P. A., Sherr, B. F., Kirchman, D., Deibel, D. (1984). Microbiology and chemistry of fecal products of pelagic tunicates: rates and fates. Bull. mar. Sci. 35: 426-439

Riley, G. A. (1970). Particulate organic matter in seawater Adv. mar. Biol. 8: 1-118

Small, L. F., Fowler, S. W., Unlu, M. Y. (1979). Sinking rates of natural copepod fecal pellets. Mar. Biol. 51: 233-241

Smayda, T. J. (1969). Some measurements of the sinking rate of fecal pellets. Limnol. Oceanogr. 14:621-625 
Smayda, T. J. (1970). The suspension and sinking of phytoplankton in the sea. Oceanogr. mar. Biol. A. Rev. 8 $353-414$

Turner, J. T (1977). Sinking rates of fecal pellets from

This article was presented by Professor $G$-A. Paffenhöfer,

Savannah, Georgia, USA the marine copepod pontella meadii. Mar Biol. 40 249-259

Vogel, S. (1981). Life in moving fluids: the physical biology of flow. Willard Grant Press, Boston

Manuscript first received: September 7, 1989

Revised version accepted: January 15, 1990 